\title{
Entrevista
}

\section{Entrevista a dos estudiantes egresadas de los estudios de Medicina}

\section{Equipo de Redacción RIECS}

Sin duda todos los estudiantes coinciden en que estudiar medicina te cambia la vida. En gran parte por la cantidad de horas que pasas en un mismo edificio rodeado de compañeros que acaban por convertirse en tu segunda familia. Blanca Ibarra y Raquel Carrasco son el ejemplo de ello: dos antiguas alumnas que hoy nos visitan para rememorar sus años en la facultad y nos explican cómo además de estudiar, hacer prácticas y distintas actividades docentes, también existe tiempo para ayudar y mejorar el día a día de todos los compañeros.

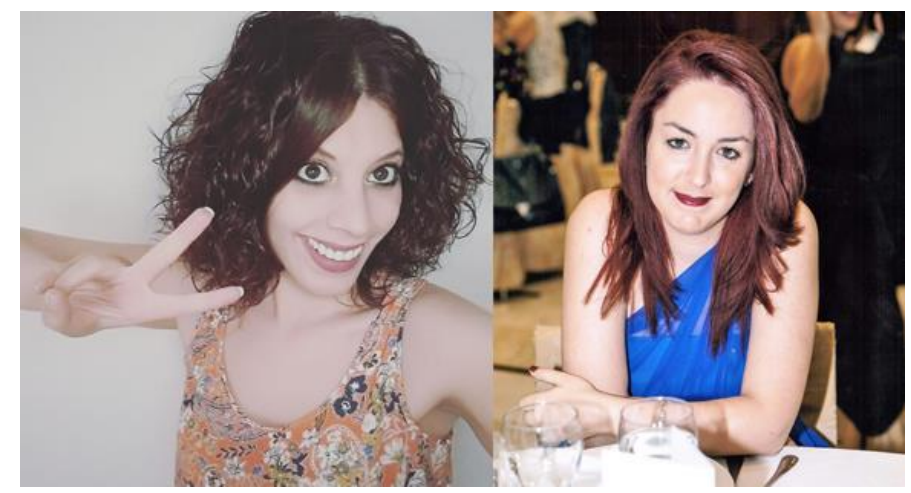

Figura 1 Raquel Carrasco (izquierda) y Blanca Ibarra (derecha)

Desde casi el comienzo de sus estudios, nuestras compañeras han pertenecido a la Delegación de Estudiantes de Medicina, además de otros órganos colegiados de la UAH (Consejo de Estudiantes, Claustro, entre otros), y han defendido la posición de los estudiantes de medicina de Alcalá ante las diversas instituciones/organismos de nuestro centro, así como ante otras facultades en el Consejo Estatal de Estudiantes de Medicina. Esta implicación en la mejora del funcionamiento de su facultad y sus estudios ha hecho que, años después de ser egresadas, hayan mantenido hasta la actualidad una relación estrecha con muchos de los que fueron sus profesores.

Por todo esto, a día de hoy siguen viniendo y colaborando con la facultad en distintas actividades, y hoy nos detenemos a hablar con ellas para que nos cuenten los momentos más emotivos de su paso por estas aulas.

Pregunta (P): ¿Qué es lo primero en lo que pensáis cuando recordáis vuestro paso por la facultad?

Blanca (B): Creo que me quedo con el primer día de facultad. Llovía a cántaros esa mañana, estaba bastante perdida, así que me acerqué a conserjería con voz tímida a preguntar dónde estaba el Aula 6. No quiero ni pensar lo que pensó de mí el conserje que me atendió o cuántas veces había respondido a esa pregunta, pero me hace pensar en la cantidad de veces que hablé con esos mismos conserjes durante los siguientes 6 años, y en el cambio que ha supuesto en mí pasar por estos pasillos. Un par de años después de pisar esta facultad por primera vez ya quedaba poco de aquella persona, ya ni te cuento cuando acabé la carrera.

Raquel (R): Es mucho lo que hemos vivido en la facultad, y es muy difícil quedarse con un solo momento. Quizás después de tanto esfuerzo para entrar, me quedaría también con el primer día de facultad. Llegamos todos con los nervios a flor de piel, entramos en un aula magna enorme e 
imponente y nos dan aquella charla de bienvenida, donde estudiar es lo primero. Después del susto inicial, nos recibieron nuestros compañeros de la Delegación, y entre aperitivos y refrescos, comenzamos al soltarnos, a conocernos. Empezaba nuestra carrera, nuestra etapa en la universidad.

\section{P: ¿Vuestro mejor momento?}

B y R: Aquí las dos coincidimos bastante. Durante la carrera supongo que los mejores momentos los vives con tus compañeros tanto dentro como fuera de las aulas. Vives tantas historias con ellos que es difícil quedarte con una. Además, que, en nuestro caso, nos conocimos trabajando en la delegación y hemos pasado muchísimas horas juntas. Sin que sirva de precedente tenemos que confesar que cuando nos conocimos no nos caímos muy bien, probablemente porque éramos y seguimos siendo muy parecidas: teníamos un temperamento muy fuerte y que apareciese otra persona casi tan cabezota como tú no nos hacía mucha gracia. Luego llegó el momento es que descubres que a pesar de ese temperamento opinas de la misma forma y eso acabó haciéndonos inseparables. Ahora aquí estamos, tras muchos años, como grandes amigas.

Solemos recordar muchos momentos juntas vividos en las reuniones de junta de facultad, consejos de departamento, es difícil quedarse con solo uno (ríen), donde descubrimos a nuestros profesores desde otra perspectiva, trabajando por y para los alumnos, teniendo en cuenta nuestra opinión como representantes y buscando soluciones para todos. Así que tal vez, teniendo en cuenta todo esto, puede que nuestro mejor momento fuese precisamente cuando nos conocimos, ya que, aunque en ese momento no nos diésemos cuenta, ese instante nos hizo vivir los mejores momentos de nuestro paso por la facultad.

\section{P: ¿Y vuestro peor momento?}

B y R: Uff... (se miran). Patología General (se ríen). No, fuera de bromas, los momentos de más angustia los vivimos cuando entramos en la dinámica de estudio; un suspenso en una asignatura puede ser un desastre y mentalmente pasa factura. Si a eso le sumas las horas en transporte público, los madrugones y el querer abarcar todo de una vez (sí los estudiantes de medicina, tenemos esa peculiaridad de ser constantes, cabezones e insistentes) sale un coctel explosivo. Pero eso forma parte del día a día y de las ganas de superarse a uno mismo y pronto con el paso de los cursos, aprendes a llevar esto de otra manera y disfrutar de la facultad en su más amplio sentido.

\section{P: ¿Volveríais a implicaros en la representación estudiantil como lo hicisteis?}

B y R: Esta es muy fácil: sin dudarlo. Creo que la representación estudiantil aporta muchísimo como estudiante y, sobre todo, como persona. Cuando conoces los problemas de la facultad, de tus compañeros, de tus profesores, empiezas a comprender a todas las partes y ver que todos formamos parte de un mismo equipo con el mismo fin. Parecen temas con poco interés, pero cuando lees normativa (quién nos iba a decir a nosotras que íbamos a dar sentido a esos documentos inmensos), también entendemos por qué ciertas cosas se pueden solicitar de una forma y otras que no. Tal vez distinguir este punto y no pedir cosas absurdas o imposibles por normativa es lo que te hace conseguir lo que los estudiantes solicitan y, a la vez conectar con el profesorado. Y sin duda es un curso intensivo de cómo hablar en público, cómo manejarnos en ambientes hostiles y todas esas virtudes que hoy en día están tan de moda. Vaya, al fin y al cabo, te enseñan a madurar.

\section{P: ¿Qué les diríais a los estudiantes que están empezando ahora su carrera de Medicina?}

B: Demasiadas cosas para plasmarlas en un papel supongo. Creo que lo más importante es que entiendan que la clave para no subirte por las paredes en ciertos momentos (que en los primeros meses ocurre muy a menudo) consiste en encontrar el equilibrio entre tiempo de estudio y descanso. Sí, sí, descanso (sonríe). Cuando el primer día los profesores te inundan la cabeza con las horas de 
estudio que requiere una asignatura hay que saber leer entre líneas. Para que el tiempo que le dedicas a la carrera sea de utilidad la mente tiene que estar despejada. Las horas de biblioteca son de estudio, pero fuera de ella existe vida. Hay que apoyarse mucho en los compañeros, desconectar, fijarse tiempos de descanso y no acabar repitiendo las inserciones musculares de anatomía mientras duermes. Si consigues esto (que se consigue), es cuando descubres que aún te queda tiempo para muchas otras cosas. $Y$, por último, que no tengan miedo a caer y cometer errores, precisamente eso es lo que les hará crecer como personas y en el futuro, les hará mejores médicos. Medicina es una carrera de fondo, no un sprint, así que simplemente hay que darse tiempo para coger el ritmo adecuado y llegar a la meta.

R: Lo primero les daría la bienvenida a una de las mejores facultades y a la carrera más bonita de todas. Ya han conseguido uno de los objetivos, poder vivir la universidad desde dentro. Hay que estudiar, sí, muchísimo, pero también hay que aprovechar todo lo que tenemos alrededor, prácticas, congresos, actividades de nuestros compañeros, de distintas asociaciones, deporte, un sin fin de cosas que hacer, que hacen que la universidad sea algo más que un lugar de paso. Aprovechar el tiempo y sobre todo disfrutar de cada una de las cosas que haces, así la motivación y la superación personal está asegurada.

(C) 2018 por los autores; licencia MDPI, Basel, Switzerland. Este articulo está distribuido en acceso abierto bajo los términos y condiciones de Creative Commons by Attribution (CCBY) licencia (http://creativecommons.org/licenses/by/4.0/). 